American Journal of Applied Science 1 (1): 18-25, 2004

ISSN 1546-9239

(C) Science Publications, 2004

\title{
Small Business Critical Success/Failure Factors in Developing Economies: Some Evidences from Botswana
}

\author{
Zelealem T. Temtime and J. Pansiri \\ University of Botswana, P.O. Box 70471, Gaborone
}

\begin{abstract}
Although the discovery of diamond has propelled Botswana from one of the poorest countries in 1966 to its current economic status as a middle-income country, the country still faces the problems of economic diversification, employment creation, income generation and distribution and poverty alleviation. Governmental and non- Governmental organizations have put many efforts on the development of small and medium Enterprises (SMEs) to diversify the economy away from mining, to create jobs, generate income and alleviate poverty. However, the pace of development of SMEs, after 30 years, is very slow. The small business failure rate is currently estimated to be over $80 \%$. There is a general consensus among policy makers, politicians and researchers in Botswana that this trend should not be allowed to continue indefinitely. The purpose of this paper is to investigate the Perceived Critical Success/Failure factors (PCSFs) affecting the development of SMEs by collecting primary data from 203 SMEs in 3 cities in the republic of Botswana through a questionnaire. Both descriptive and inferential statistics were employed to present the empirical data. The findings showed that ten PCSFs (human resources development; organizational development, managerial background; managerial leadership and competitive strategy) affect the performance of SMEs. The PCSFs are strongly related among themselves, indicating the need for a holistic and systematic approach in addressing them. Important relationships were also found between the PCSFs and firm-specific demographic variables such as ownership status, experience and operation period. Recommendations and implications for the policy and research are also forwarded.
\end{abstract}

Key words: Small and medium enterprises, developing economies, perceived critical success/failure factors, entrepreneurial development, Botswana

\section{INTRODUCTION}

Since its independence in 1966, Botswana has achieved a remarkable growth in economy, sociopolitical stability and education. Its current political administration, which is one of the leading democratic systems in the world, is based on equity in the distribution of resources and services. Although the discovery of mineral wealth [i.e., diamond] has propelled Botswana into the middle-income category, the country still faces the problem of economic diversification, employment creation, income distribution and poverty alleviation. The country's economy is highly dependent on the mining and beef sectors for its income and on foreign markets for the import of basic goods and services. Although the government of Botswana has designed various diversification programs and policies, the main focus has been on the promotion of the development of Small and Medium Enterprises (SMEs).

The most common argument in favor of SMEs is that they create substantial job opportunities as they use relatively labor-intensive technologies. SMEs employ more people per unit of investment as compared to large firms. Thus, a given amount of money will create more jobs if it is spread over a large number of SMEs than if it is focused on few large companies ${ }^{[1]}$. The major and immediate challenge for Botswana is providing employment for low-skill labor. The declining job opportunities in the South African mines in Botswana, the prevalence of low-skill and unskilled labor force in the economy and the tendency of the government to reduce its role as the primary employer made the promotion of SMEs a primary sources of employment creation.

SMEs contribute not only to income generation but also income distribution. Large firms normally tend to produce an elite number of high wage income earners whereas SMEs produce a significantly large number of relatively low-income earners. The development of SMEs would therefore help spread income to more people. Since the majority of Botswana (over 65\%) is living in rural areas, the promotion of the development of SMEs should continue to be a policy priority to narrow the gap between urban and rural development and to monitor social inequities and rural migration. SMEs also promote the culture of saving and investing in society. The money invested in SMEs would probably have been allocated to consumption expenditure if SMEs have not been established or sought for it. This nature of propensity to save and invest, induced by the development of SMEs, can directly contribute to the overall savings ratio of the population of Botswana. 
Enhancing the poverty alleviation potential of SMEs through financial, regulatory and management assistances will eventually reduce dependency on foreign markets. This will not only save foreign exchange but also reduce the impact, which fluctuations of foreign exchange receipts will have domestically. The promotion of the development of SMEs will, therefore, have a long run effect of economic independence and sustained sovereignty and autonomous development.

Although great efforts were made to promote the development of SMEs, they are still at their survival/existence stage, with more emphasis being placed on short-term survival issues than growth and long-term competitiveness ${ }^{[2]}$. It is estimated that the general failure rate for SMEs in Botswana is over $80 \%$, with over $70 \%$ of start-up firms failing in their first 18 months and only less than $2 \%$ of them expand their businesses [government paper no. 1 of 1999]. This has called for the need to investigate and understand the critical factors affecting the development of SMEs in the Botswana context. This will eventually enable policy makers, practitioners and other SMEs stakeholders identify the major problems and design effective assistance schemes and a proactive entrepreneurial development program

\section{MATERIALS AND METHODS}

The objective of the study is to investigate the critical success factors affecting the performance and development of Small and Medium Enterprises (SMEs) and analyze the relationship between these factors and firm specific demographic variables and the association among the critical success factors themselves, for the purposes of designing a proactive entrepreneurial development program in Botswana. Data were collected from three cities through questionnaire from 250 SMEs during the period between April and November 2002 and analyzed using both descriptive and inferential statistics.

First, demographic characteristics of the respondents were tabulated and presented to show the distribution of the sample firms in different demographic variables. Second, a data reduction (Principal component analysis) and purification (Varimax rotation) were conducted to identify the most critical success factors and to measure the reliability and validity of the measurement instrument. Third, the critical factors were compared and ranked according to their perceived mean values. Forth, the relationship between critical success factors and demographic variables was measured by using descriptive statistics (mean scores) and inferential statistics (F-tests). Fifth, the association between the critical success factors was measured by conducting partial correlation analysis. Finally, a summary of the findings of the study was presented.
Demographic characteristics of the sample firms: The first part of the questionnaire was designed to gather information about firm characteristics. Although 250 questionnaires were expecting only 221 were completed and returned during the eight months (AprilNovember 2002) data collection period. Out of these, 203 (92\%) were found used in the study. 18 questionnaires were discarded due incompleteness and large number of missing values.

The majority $(70 \%)$ of the sample firms were small with 6-25 full time paid employees, $14 \%$ were micro with up to five employees, while the remaining $15 \%$ were medium sized companies with number of employees ranging from 26-99. The majority of the respondents were males (68\%) indicating the low participation of women (28\%) in top managerial positions in the private sector. Most of the sample firms (65\%) were taken from Gaborone, while 20 and $15 \%$ were selected from Francis town and Lobatse, respectively. $65 \%$ of them were from the merchandising (retail and wholesale) industrial, while $25 \%$ were operating in the service industry. Only $10 \%$ were from the manufacturing industry. Most (69\%) of the firms were established as corporations whereas the remaining are organized or registered as a sole proprietorship (13\%) and partnership (11\%). All the respondents do not have a similar status in their company. Some are owner mangers $(11 \%)$ others are part owner managers $(33 \%)$. But, the majorities $(55 \%)$ of the respondents are employed full time managers. Only $21 \%$ of managers of the sample firms have below 5 years experience while the remaining $73 \%$ have over 5 years general managerial experience. However, most of them (55\%) have been managing their current company for less than five years. Only $9 \%$ of them have over ten year's management experience, while $36 \%$ of them have since 6-10 years managerial experience with their current company. Most of the sample SMEs $(62 \%)$ has been operating in the Botswana economy since 6-10 years, while $19 \%$ of them operated for over 10 years. Only $17 \%$ of them were established in the past five years. The majority of the owners are foreigners $(53 \%)$. Botswana citizens own $34 \%$ of the sample firms whereas both foreigners and locals owned the remaining $7 \%$.

Critical success/failure factor analysis: The data collection instrument contained 76 items under four theoretical categories (environmental, managerial, marketing and finance) and the respondents were asked to evaluate the perceived impact of these items on the performance of SMEs on a five-point scale ranging from 5 (very high) to 1 (very high) to 1 (very low). The respondents have assigned scores to each of the 76 factors. Since it is difficult to analyze and compare these 76 items, they were factor analyzed and grouped into manageable number of problem categories using the principal component analysis of the SPSS program version 11.5. 
Table: 1 Items rejected from analysis due to low factor loadings

\begin{tabular}{|c|c|c|c|}
\hline Rejected items with very low or no loadings & $\mathrm{N}$ & Mean & Std. D \\
\hline Competing with larger firms locally & 200 & 3.05 & 1.325 \\
\hline Attracting and recruiting suitable staff & 203 & 3. 00 & 1.311 \\
\hline Experience in owning running a business & 200 & 2.53 & 1.337 \\
\hline Business location/business site & 200 & 3.38 & 1.234 \\
\hline Credit facilities and sources in the economy & 200 & 3.39 & 1.247 \\
\hline Accessibility of growth financing sources & 196 & 3.54 & 1.250 \\
\hline
\end{tabular}

Table 2: Reliability coefficients of CSFS

\begin{tabular}{|c|c|c|c|c|c|c|c|}
\hline Rank & CSFs & CODE & ITEMS & CASES & ALPHA & Mean & S.D \\
\hline 1 & Customers relationship & CRN & 6 & 189 & 0.872 & 3.36 & 0.90 \\
\hline 2 & Organizational design & ORD & 7 & 181 & 0.849 & 2.82 & 0.98 \\
\hline 3 & Managerial background & MAB & 5 & 198 & 0.821 & 2.76 & 1.04 \\
\hline 4 & HRM development & HRD & 8 & 183 & 0.818 & 3.05 & 0.90 \\
\hline 5 & Working capital & WCM & 7 & 183 & 0.797 & 3.36 & 0.85 \\
\hline 6 & Marketing activities & MKT & 7 & 185 & 0.678 & 3.46 & 0.70 \\
\hline 7 & Managerial activities & MAC & 5 & 190 & 0.695 & 3.28 & 0.71 \\
\hline 8 & Investment analysis & IAN & 7 & 182 & 0.649 & 3.42 & 0.68 \\
\hline 9 & Socio-economic & SOE & 8 & 179 & 0.631 & 3.19 & 0.66 \\
\hline 10 & Changes & $\mathrm{CHG}$ & 4 & 184 & 0.512 & 2.89 & 0.85 \\
\hline 11 & Competitive strategy & COS & 4 & 184 & 0.397 & 2.62 & 1.56 \\
\hline 12 & Personal factors & PRF & 2 & 195 & 0.210 & 2.11 & 1.72 \\
\hline
\end{tabular}

Table 3: Mean ranking of marketing action items

\begin{tabular}{llll}
\hline Rank & Marketing action items & N & Mean \\
\hline 1 & product/service marketing & 196 & 3.62 \\
2 & marketing research and information & 200 & 3.57 \\
3 & Demand forecasting and analyzing & 200 & 3.42 \\
4 & Pricing policy and strategy & 200 & 3.105 \\
5 & Trained sales staff and promoters & 197 & 1.053 \\
6 & market segmentation & 196 & 1.133 \\
\hline
\end{tabular}

The original four theoretical categories were extended to 12 derived factors. The original environmental factors split into two derived factors (socioeconomic and techno-regulatory factors). This means that environment related items were loaded onto socioeconomic and techno-regulatory factors. Items related to managerial issues were loaded onto four newly derived factors (organizational developments, HRM development, management background and managerial action). Items related to marketing were loaded onto two factors (customer relationship and marketing action). Similarly, items related to finance were loaded onto two factors (investment analysis and working capital management). The principal component analysis has therefore reduced the data into 12 Critical Success Factors (CSFs) containing 70 items. The remaining 6 items did not load onto any of the 12 CSFs and hence rejected from the analysis (Table 1). Then, a reliability analysis was conducted on the 12 factors to measure the internal consistency of the items loaded onto each factor. Cronbach's alpha or reliability coefficient shows the internal homogeneity among the 70 items comprising the 12 derived factors. In other words, it reveals the extent to which the same set of respondents replied in a consistent manner to similar items.

All Cronbach's alpha values except for two factors were in excess of 0.5 , giving $10 \mathrm{CSFs}$ according to ${ }^{[4]}$ $\alpha \geq 0.50$ meets the requirements for basic survey research. Thus, a cutoff value of 0.05 was used to measure reliability and 10 factors were accepted as Critical Success Factors (CSFs) affecting the performance of SMEs (Table 2).

The Customer Relationship factor (CRN) consists of 6 interrelated items that are more consistently responded to by 189 respondents and has the highest reliability coefficient of 0.872 . This means that Customer Relationship (CRN) is a reliable measurement of the 6 items. As the last two factors have and alpha value of less than the cutoff point of 0.5 , they were excluded from the study.

A summary of the main impact of the 12 factors is also presented in Table 2. It should be noted that all these factors are critical to the performance of SMEs. But, all factors do not have an equal degree of importance as perceived by the respondents.

Marketing Action: Customers rated the marketing action factor, which contain 7 items, highest (mean = 3.46) in terms of its impact on the performance of SMEs. This is in line with the findings of previous studies $^{[5]}$. Found marketing activities to be the most important factor affecting the performance of small firms. Detailed analysis of the mean values of the 7 marketing related items shows that product/service marketing (mean $=3.62$ ) has contributed most significantly to the marketing factor (MKT) than the other six items. 
Since small firms have very limited resources to solve their problems, it is essential to prioritize those items that have greater impact on their success than do others. As shown above market segmentation has a relatively less impact on SMEs than other marketing related items like product marketing and marketing research and information. Understanding the impact of different activities would enable SMEs support agencies and practitioners to find practical solutions. This finding is in line with the findings of other previous studies ${ }^{[6]}$. For example, found sales and marketing issues as critical success factors for SMEs. He specifically reported that promotion, marketing research and training are more important than other activities ${ }^{[7,8]}$. Also acknowledged marketing activities as being the most important factors affecting small business success.

Investment analysis: The investment analysis factor is rated second and includes 7 items. The performance of SMEs is affected by lack of insufficient provision for contingencies, high investment in fixed assets particularly during start up stage, inadequately estimated capital requirements, inability or failure to analyze financial statements, misperception of turnover as profit and under utilization of company assets. All these items have significantly contributed to the importance of investment analysis in SMEs. The major contributors to this factor are high investment in fixed assets (mean $=3.75$ ) and the use of inadequately estimated capital when starting a business (mean = 3.50). SMEs do not usually use external advisers when making decision on the amount of capital they need. Lack of investment analysis may result in the use of right sources of capital for wrong purposes; or the wrong sources of capital for the right sources for the right purposes. High investment in fixed assets means that a huge sum is unnecessarily tied up in fixed assets. Start up firms must not tie their initial capital in cannot be realized in the near future.

Working capital management: Working capital management deals with the process of planning and controlling current assets and current liabilities for smooth organizational operations. Problems in the management of credits and overdrafts, poor cash flow analysis, poor management inventory, cash, account payables and receivables and unplanned withdrawal of cash may have a devastating impact on the performance of SMEs. Failure in collecting accounts receivables may have serious impact on liquidity and settling shortterm credits and overdrafts. The respondents indicated that poor management of inventory indicated that poor management of inventory $($ mean $=3.54)$, poor management of cash $($ mean $=3.53)$ and unplanned withdrawal of cash (mean $=3.50$ ) are the most influential problems related to working capital management. These problems may also lead to of caused by investment analysis related problems. Excessively high investment in fixed assets may lead to lack of resources to buy current assets or to settle current liabilities.

Sometimes cash will be tied up in accounts receivable as credit sales to customer increases. Sometimes cash will be tied up in accounts receivable as credit sales to customer increases. Sometimes they postpone repayment of short-term liabilities until it becomes a threat to them. Sometimes they hold unnecessarily large inventory tying up their limited capital. Cash is the net outcome of the activities of a business. If SMEs is operating efficiently, the operating cycle moves smoothly through the cash-to-inventoryto-receivables-to cash stages and final decisions are concerned with the distribution of residual cash. If the cash conversion cycle is interrupted or if the flow is distorted, financial problems ensue that may have grave consequences if they are not quickly worked out ${ }^{[9]}$. Mismatching sources and uses of funds are also a major problem. The liquidity problem of startups is associated with day-to-day decisions. Small firms often fail to distinguish between long and short term financing needs and to find appropriate sources. It is not uncommon to see start ups using short term financing for long-term assets. Many starts up firms experience a mismatching of funding sources and uses ${ }^{[5]}$.

Customer relationship: Today quality has become the basis of global competition. Competitiveness and survival are possible if only SMEs can provide quality product/services and achieve customer satisfaction, which leads to customer loyalty-a prime determinant of profitability. It is easier to retain existing customers than attracting new ones. Customer relationship includes keeping customer records, making follow-up on customers behaviors, improving knowledge of their characteristics, understanding the market complexity and having adequately trained staff. The respondents placed more emphasis on keeping customer records (mean $=3.48)$ and follow-up on customer behavior $($ mean $=3.39)$. It seems, from the data, that SMEs have a clear understanding of the important role played by establishing customer relationships. But, the tradeoff between perceived cost of establishing the relationship and the possible economic benefits of the relationship seems unclear.

Managerial action: Many researchers and practitioners claim that the major cause of small business failure is "poor management". Whether the causes are labeled ad financing, competition, marketing, inventory, they can be safely avoided if good management was in place. Although it has become difficult to explain what constitutes 'poor management' small business owners/managers need to develop basic managerial skills and knowledge. If they are to succeed, managers 
need to have adequate skills in the area of planning, organizing, directing and controlling organizational resources. The respondents have clearly recognized the importance of managerial adequacy and competency as critical success factors.

The main contributor to the critical role of the managerial factor is the use of external advisors (mean $=3.45$ ), focus on strategy formulation and implementation rather than focusing on operational bits and pieces $($ mean $=3.42$ ), aiming for long term competitive advantages rather than short term profits (mean $=3.26)$, and developing a strong interest for nonfinancial benefits such as need for achievement and recognition $($ mean $=3.23)$.

Socioeconomic issues: socio economic issues include social, cultural and demographic changes in the external environment that affects the performance of SMEs. Economic issues include impacts of inflation, recession, changes in interest and exchange rates, market size, spending power of customers, availability of business premises in the community, intensity of competition in the market. The respondents evaluated these items and perceived them to be critical success factors for SMEs. However, compared to other factors like marketing and managerial actions, they rated it sixth (mean $=3.19$ ). The most influential items that have significantly contributed to the socioeconomic factor are intensity of competition $($ mean $=4.04)$, small market size $($ mean $=$ 3.54 ), availability of affordability of business premises $($ mean $=3.42)$, the impact of inflation, interest and exchange rates $($ mean $=3.26)$ and low spending power of customers (mean $=3.10)$ are rated to have significant impact on SMEs.

However, the prevalence of crime and violence in the vicinity (mean $=2.59$ ), the impact of national culture on productivity (mean $=2.66$ ) and the impact of HIV/AIDS were rated by the respondents to have relatively little impact on the performance of SMEs. This is in contrast to the findings of the study conducted by ${ }^{[10]}$ in South Africa. They concluded that culture, crime and violence coupled with the widespread of HIV/AIDS are exerting much pressure on the survival of SMEs in South Africa. The impact of government financial assistance and policies on small firms and found them to be critical for the survival of many smaller start-up-firms ${ }^{[9]}$.

Human resource development: The respondents indicated that human resources development is a critical success factor affecting the performance of SMEs. But, its perceived impact on SMEs is relatively low (mean = 3.05). Out of the eight human resources development related items, lack of experienced employees in the market (mean $=3.52)$, lack of skilled manpower in the market (mean $=3.45$ ), lack of low cost training facilities (mean $=3.22)$ and inaccessibility and unavailability of training facilities in the community (mean $=3.06)$ are considered to be more important than other HR development issues such as employee turnover (mean $=2.05$ ) and dependence on family labor $($ mean $=2.55)$. The important finding at this is that according to the SMEs perception of the market, the major problem is not shortage of manpower. There are two major problems- (1) lack of skilled and well experience personnel in the labor market and (2) accessibility to our lack of low cost training facility in the community. Although this finding is in line with those of previous studies, there is one exception. Most previous studies, there is one exception. Most previous studies attach greater importance to the use of HR development policies than to any other factor. But, our sample SMEs considered HRD policies to have little impact on firm performance $($ mean $=2.88)$. This could be attributed to many factors including misconception of the word HRD.

Techno-regulatory changes: SMEs are facing challenges brought about by changes in technology and political-legal environment. Technology changes the way SMEs is doing business. They must be able to keep abreast of the changes in technology. New technology is usually expected to reduce cost of product or service. Failure not to employ the latest technology means producing at a higher unit cost than do others who use new technology. Civil war, political instability, market policy, taxation policy, price control, regulation or deregulation of some industries may affect small business success. The respondents perceived the changes in technology to be more critical $($ mean $=$ 3.18) to SMEs than the other items [company registration $($ mean $=2.99)$, labor legislation $($ mean $=$ $2.68)$ and trade unions $($ mean $=2.68)$ ]. This implies that the legal and political environment is considered as exerting less pressure on SMEs than rapid and costly technological changes.

Organizational development: The way SMEs are organized or structured has and important implication for the flow of information and effectiveness of communication in the organization. Organization structure affects unity of command and unity of chain as well as the flow of authority and responsibility in the organization. They clarify issues like who reports to whom and the job description and content of each organizational member. The respondents considered organizational development as a critical success factor $($ mean $=2.82)$ with a lower perceived impact on SMEs than do other factors.

Centralized decision making $($ mean $=3.09)$, lack of a clear division of activities (mean $=2.89$ ), low level of formalization $($ mean $=2.87$ ) and high span of control (mean $=2.86)$ are considered to be more influential than other activities like level of standardization (mean $=2.63)$, organizational structure $($ mean $=2.75)$ and 
communication problem $($ mean $=2.79$ ). This is not surprising, as most SMEs in the developing economies do not have formal organizational structure, line of communication, formalization and standardization policies. But, many studies confirmed that standardization of products or services, organizational structure and communication effectiveness are more influential than the other.

Managerial background: Managerial background includes basic requirements to be a professional manager. These are general educational background. Training in basic business management skills and practical industry experience. The respondents considered it as small business critical; success factor with a lower mean value of 2.76. The ranking of managerial background as least influential is in contrast to theory and the findings of other previous studies. The respondents perceived the items related to management education, training and experience as having only little impact on the performance of SMEs. But, many studies found managerial background as having greater impact on SMEs than do any other factors. This could be attributed to the concentration of the sample firms in non-manufacturing sectors where managerial background has a relatively less impact on organizational performance than on manufacturing firms. The other possible reason for such perceptions may lie in the fact that many companies in Botswana are extensions of branches of other companies located in South Africa and Zimbabwe. In these cases, managerial leadership flows from the headquarters. The next least affecting factor is organizational design and development. This factor comprises such items as lack of a clear division of labor, lack of open communication, lack of proper organizational structure, low level of standardization of products/service and formalization of working procedures. This is again in contrast to the findings of many previous studies conducted on large firms. There is of course lack of adequate evidence to witness that these organization designs related items critically affect the development of SMEs in developing economics.

\section{DISCUSSION}

The majority of the sample firms were small in size (with less than 26 employees) and only a very few firms were found to be medium in size (with full time paid employees ranging from 26-99). Thus, the Botswana economy is largely dominated by small firm operating in various sectors. The number of manufacturing firms is far less than the number of service companies showing smaller industrial base in the Botswana economy. The majority of the sample firm was legally organized as corporations and sole proprietorship firms. The data show that the partnership form organization is not common in Botswana. The sample firms have been operating in Botswana on average for over 5 years. The owner/managers of SMEs had a managerial experience ranging from 5-10 years on average. These people have also managed their current companies for over 5 years. The majority of the sample firms were owned by either foreigners or jointly by citizens. The sources of capital fall under the two traditional sources-own saving and bank/government loan.

Critical success factor: The respondents rated the perceived impact of 76 items on the performance of their business. Using the principle components analysis program of the SPSS software, version 11.5, the 76 items were reduced to 10 critical success factors with an acceptable degree of reliability. 70 items were loaded onto the 10 critical factors. But, the remaining 6 items did not load significantly on any of the 10 categories. As this show lack of correlation between the 6 items and the 10 categories, the items were excluded from the study. Thus, the study is based on the evaluation of the 70 items as grouped under 10 critical success/failure factors.

The study showed that marketing activities such as product marketing, market research, demand forecasting and so forth were perceived by the respondents to have greater impact on their business than any other factor. This should be seen in relation to the nature of the service industry where most of the sample firm was taken from. The performance of service firms could be drastically affected by marketing activities. Investment analysis and working capital management related problems were also rated by respondents as having significant impact on small business performance. Identifying the right source of capital for the right purpose is a challenge for SMEs. Proper management of fixed capital may lead to proper implementation of strategic plans while the proper management of working capital minimizes short-term obstacles to achieve competitive advantage in the marketplace.

Customer relationship was also rated highly by the respondents in its impact on the performance of firms. Service and merchandising firms spent much time and response to retain their customers. Customer loyalty and retention have been the main strategy for these firms to achieve competitiveness.

Managerial actions and socioeconomic related problems were also identified as critical success factors for SMEs. The study found that poor use of external advisers by small business owners/managers' is the major problem affecting SMEs development. Managerial functions in SMEs are limited to routine short-term focused activities and very little emphasis has been given to long-term competitiveness and profitability. Socioeconomic factors also play important role in the development of SMEs. The degree of 
intensity of competition was rated as having the greatest impact on firm performance. It is not difficult to imagine how SMEs with inadequate managerial orientation can operate effectively in today's turbulent markets characterize by the high intensity of global competition. In contrast to the South African findings ${ }^{[10]}$, the respondents put very little emphasis on HIV/AIDS, crime and violence as affecting the performance of SMEs. But, the availability of business premises was rated high as a critical factor for SMEs in Botswana.

Human resource development and technical and regulatory factors were also considered by the respondents as impacting the performance of SMEs. The major HRM related problem includes lack of wellexperienced and trained employees in the labor market. These problems were also accompanied by a lack of low cost and accessible training facilities in the economy. The respondents, however, showed that the impact of the company registration process, the national labor legislation and the relationship with trade unions is perceived to be lower than the impact of other factors.

Organizational development and managerial background of owners/managers were also considered as critical success factors for SMEs. Organizational development related problems include formalization of working procedures, standardization of services, Organizational structure and communication channels. Any educational or material assistance to the development of SMEs should also address these problems. In contrast to previous studies, the respondents placed a low level of importance of managerial background as a critical success factor. This could be attributed to the fact that most managers or owners of failed SMEs do not accept the fact that their lack of managerial education and training is also responsible for their failure.

Implications: The findings show three important implications for SME support groups including the government, practitioners in SMEs, and researchers and academics in the areas of entrepreneurship and small business development. First, the designing and implementation of small business assistance programs should be based on the identification and prioritization of critical success factors. All problems do not have an equal degree of complexities, magnitude or impact on small business performance. Different problems with different degree of perceived impact on SMEs can be addressed at different times in different ways depending on the availability of resources and situations in the operating environment. A proactive entrepreneurial development programs require a long-term view of the current problems. The study of small business problems must target on finding long lasting and sustainable solutions. Entrepreneurship cannot develop in a vacuum. Efforts must be made to incorporate entrepreneurship into the national culture and way of life. This calls for the integration of entrepreneurship with school curriculum starting from kindergarten. Currently, there is a widening gap between education institutions (schools, colleges and university) and the actual world of work. The study of small business problems must find strategies to bridge or narrow this gap and focus on building long term potential. The increase in the number of small businesses in the economy should not be equated with the development of entrepreneurship in the country. These are two different constructs. It is the development entrepreneurship that leads to an increasing number of viable small firms, not vice versa. Thus, the implication of this study for small business support group is that the development of a proactive entrepreneurial program should be based on an empirical investigation of small business problems, with the view to achieve long-term sustainable solution. SMEs support groups including the government should focus on building competitive potential of indigenous firms through not only material and financial assistance but also though education, training, strategic awareness program and entrepreneurial orientation. The target should not be increasing the number of SMEs but to achieve changes in the entrepreneurial attitude of the people of Botswana at large. Second, the research design, operationalization and conceptualization of small business critical success/failure factors need to be reexplored.

\section{REFERENCES}

1. Asri, A. And M. Baker, 2000. Small and Medium Enterprises in Asian Pacific Countries (Eds), Science Publishers Inc., Huntington, New York.

2. Temtime, Z.T., 2000. The planning behavior of small and medium enterprises in Botswana. 4th International Conference on Entrepreneurship, Dar Es Salaam, Tanzania.

3. Government of Botswana, 1999. Policy on Small, Medium and Micro Enterprises in Botswana, Government White Paper NO. 1, Government Printing Press, Gaborone.

4. Nunally, J., 1978. Psychometric Theory. 2nd Edn., McGraw Hill, New York, NY.

5. Watchman, H., 1990. Account in and marketingkey small business problems. Am. J. Small Bus., 7: 19-26.

6. Walsh, J.P., 1988. Selectivity and selective perception: An investigation of manager's belief structures and information processing. Acad. Mange. J., 31: 873-896. 
7. McKenna, P., 1991. Marketing is everything, Harvard business review, January-February, pp: 65-79.

8. Romano, C. And J. Ratnatunga, 1995. The role of marketing: Its impact on small enterprise research. Eur. J. Market., 29: 9-30.

9. O'Niell, H.M. and Duker, 1986. Survival and failure in small business. J. Small Bus. Manage., 30-37.
10. Suzzette, V., Shally Van Eden and D. Venter, 2001. Identifying small business problems in the South African context for a proactive entrepreneurial program. A Paper Presented at the Global Int Ent 2001 11th International Conference, July 2-4, Kruger National Park, South Africa 